\title{
Does Marriage and Relationship Education Work? A Meta-Analytic
} Study

\author{
Alan J. Hawkins \\ Brigham Young University - Provo, hawkinsa@byu.edu \\ Victoria L. Blanchard \\ Brigham Young University - Provo \\ Scott A. Baldwin \\ Brigham Young University - Provo \\ Elizabeth B. Fawcett \\ Brigham Young University - Provo
}

Follow this and additional works at: https://scholarsarchive.byu.edu/facpub

Part of the Other Social and Behavioral Sciences Commons

\section{Original Publication Citation}

Hawkins, A. J., Blanchard, V. L., Baldwin, S. A., \& Fawcett, E. B. (2008). Does marriage and relationship education work? A meta-analytic study. Journal of Consulting and Clinical Psychology, 76, 723-734.

\section{BYU ScholarsArchive Citation}

Hawkins, Alan J.; Blanchard, Victoria L.; Baldwin, Scott A.; and Fawcett, Elizabeth B., "Does Marriage and Relationship Education Work? A Meta-Analytic Study" (2008). Faculty Publications. 4225.

https://scholarsarchive.byu.edu/facpub/4225

This Peer-Reviewed Article is brought to you for free and open access by BYU ScholarsArchive. It has been accepted for inclusion in Faculty Publications by an authorized administrator of BYU ScholarsArchive. For more information, please contact ellen_amatangelo@byu.edu. 


\title{
Does Marriage and Relationship Education Work? A Meta-Analytic Study
}

\author{
Alan J. Hawkins, Victoria L. Blanchard, Scott A. Baldwin, and Elizabeth B. Fawcett \\ Brigham Young University
}

\begin{abstract}
In this meta-analytic study, the authors examined the efficacy of marriage and relationship education (MRE) on 2 common outcomes: relationship quality and communication skills. A thorough search produced 86 codable reports that yielded 117 studies and more than 500 effect sizes. The effect sizes for relationship quality for experimental studies ranged from $d=.30$ to .36 , while the communication skills effect sizes ranged from $d=.43$ to .45 . Quasi-experimental studies generated smaller effect sizes, but these appeared to be due to pretest group differences. Moderate-dosage programs produced larger effect sizes than did low-dosage programs. For communication skills, published studies had larger effects than those of unpublished studies at follow-up; there were no publication differences for relationship quality. There was no evidence of a gender difference. Unfortunately, a lack of racial/ethnic and economic diversity in the samples prevented reliable conclusions about the effectiveness of MRE for disadvantaged couples, a crucial deficit in the body of research. In addition, intervention outcomes important to policy makers, such as relationship stability and aggression, rarely have been addressed.
\end{abstract}

Keywords: family policy, marriage and relationship education, meta-analysis, program evaluation

The science of prevention of human problems continues to grow and show promise (Flay et al., 2005; Rishel, 2007). In addition to the prevention of individual mental health problems, prevention efforts also include educational interventions to help romantic couples form and sustain healthy marriages and relationships. Marriage and relationship education (MRE) consists of two general components. The primary emphasis has been on developing better communication and problem-solving skills that are core to healthy, stable relationships, such as diminishing criticism and contempt and improving listening skills (Gottman \& Silver, 1999). Couples learn about the importance of these skills and usually practice them with some instructor guidance. A second component of MRE is didactic presentation of information that correlates with marital quality, such as aligning expectations and managing finances. Couples learn about and discuss these issues and often make specific plans for dealing with them more effectively. Often within this component are discussions about important virtues related to relationship quality, such as commitment and forgiveness (Fincham, Stanley, \& Beach, 2007). While some MRE programs emphasize one component to the exclusion of the other, most combine the two, and most of these give more emphasis to communication skills training. While many couple therapists also provide MRE services, MRE is distinct from couple therapy. MRE does not provide intensive, one-on-one work between participants and professionals on specific personal problems, as therapy does.

Alan J. Hawkins, Victoria L. Blanchard, and Elizabeth B. Fawcett, School of Family Life, Brigham Young University; Scott A. Baldwin, Department of Psychology, Brigham Young University.

We thank Matt Stagner and the Urban Institute for their permission to use their database of marriage and relationship education studies.

Correspondence concerning this article should be addressed to Alan J. Hawkins, 2050 JFSB, Brigham Young University, Provo, UT 84602-6723. E-mail: hawkinsa@byu.edu
MRE provides "upstream" educational interventions to groups of couples and individuals before problems become too serious and entrenched (J. H. Larson, 2004).

Over the last decade, MRE has grown beyond programs offered by private professional and lay practitioners to become a tool of public policy. For example, U.S. federal policy makers recently have supported MRE as a way to help couples-especially lowerincome couples-form and sustain healthy marriages as an additional tool to reduce poverty and increase children's well-being (Administration for Children and Families, 2007; Dion \& Hawkins, 2008). In 2006, federal legislation allocated \$500 million over 5 years to support promising MRE programs and initiatives targeted primarily at lower-income couples. (See http:// www.acf.hhs.gov/programs/ofa/hmabstracts/index.htm for a listing of funded programs.) In addition, a growing number of states have also allocated significant public funds to support MRE efforts (Ooms, Bouchet, \& Parke, 2004). For instance, Texas has dedicated more than $\$ 10$ million a year to support MRE; Utah has dedicated $\$ 750,000$ a year. With greater public support for MRE, however, comes greater public scrutiny (Huston \& Melz, 2004).

Scholars have conducted many evaluation studies of various MRE programs over the past three decades (Halford, 2004; Halford, Markman, Kline, \& Stanley, 2003). Previous meta-analytic reviews of MRE research have generally shown it is effective in increasing relationship quality and communication skills (Butler \& Wampler, 1999; Carroll \& Doherty, 2003; Giblin, Sprenkle, \& Sheehan, 1985; Hahlweg \& Markman, 1988; Hight, 2000; Reardon-Anderson, Stagner, Macomber, \& Murray, 2005). However, these studies have been limited in their conclusions. The first meta-analysis of MRE is more than 25 years old (Giblin et al., 1985). The most recent meta-analysis (Reardon-Anderson et al., 2005) did not include quasi-experimental studies, studies that may be more representative of MRE as it is practiced under normal field conditions (Shadish, Matt, Navarro, \& Phillips, 2000). Two studies reviewed only a narrow band of the marriage education 
spectrum - premarital education (Carroll \& Doherty, 2003; Hahlweg \& Markman, 1988). Another focused only on one specific program-Couples Communication (Butler \& Wampler, 1999). Two meta-analyses did not distinguish between therapy and educational interventions for couples (i.e., Giblin et al., 1985; Reardon-Anderson et al., 2005). One meta-analysis was an unpublished dissertation (Hight, 2000) that did not differentiate between relationship quality and communication skills outcomes, although it was the only meta-analysis that gave significant attention to unpublished studies. Moreover, moderator variables important to practitioners and policy makers, such as gender differences, ethnic/ racial diversity, and economic diversity of participants, have not been investigated extensively.

Our meta-analytic study addresses these limitations. Our primary aim is to address the following question: Does the overall evidence suggest that MRE can help couples form and sustain healthy relationships? Specifically, we evaluate the efficacy of MRE for relationship quality and communication skills at both immediate postassessment and follow-up assessment. We also explore several important methodological, sample, and intervention variables that may moderate the effects of MRE.

\section{Method}

\section{Selection and Inclusion Criteria}

Psychoeducational intervention. In the current meta-analysis, all studies assessed the effects of a psychoeducational intervention that included improving couple relationships or communication skills as a goal. Therapeutic interventions were excluded to provide a clear picture of the effects of psychoeducational intervention. Therapeutic interventions generally have stronger effects than do psychoeducational interventions (Shadish \& Baldwin, 2003). Thus, we excluded studies that had set curricula but were delivered by a therapist to a couple as well as programs that were essentially group therapy (e.g., Worthington et al., 1997). Studies that focused on improving sexual functioning were excluded (e.g., Cooper \& Stoltenberg, 1987).

Reporting of outcome data. We included studies that reported sufficient information to calculate effect sizes for the specified outcomes. When studies did not report sufficient information to calculate effect sizes, we contacted the authors where possible for more information and used methods for "rehabilitating" studies outlined by Lipsey and Wilson (2001). Six studies (5\%) were dropped because we could not calculate an effect size.

Outcome measures. We coded measures of relationship quality that assessed various aspects of relationships such as areas of agreement-disagreement and conflict, time together, and areas of satisfaction-dissatisfaction. Some measures simply asked about overall relationship satisfaction. We included these measures as a subset of the broader construct of relationship quality. Most studies $(k=112)$ used standardized measures, such as the Dyadic Adjustment Scale (Spanier, 1976) or the Marital Adjustment Test (Locke \& Wallace, 1959). Communication skills were reported in numerous ways, including global assessments, positive and negative communication, positive problem solving, and negative problem solving, with both self-report and observational measures employed. We combined all these measures into a single, communication outcome indicating a global intervention effect on communication skills.
We examined both immediate postassessments and follow-up assessments, reporting these separately to explore deterioration (or gain) over time. Timing of follow-up for experimental studies ranged from 1 to 60 months; 3 - and 6-month follow-ups were most common. Timing of follow-up for quasi-experimental studies ranged from 1 to 36 months; again, 3- and 6-month follow-ups were most common. When multiple follow-up assessments were available, we chose the assessment closest to 12 months. Only a handful $(k=7)$ of studies employed follow-up assessments greater than 12 months. For instance, Schulz, Cowan, and Cowan (2006) evaluated the effects of their transition to parenthood MRE intervention at 6-, 18-, 42-, and 60-months postpartum. Although we coded the follow-up closest to 12 months to allow for more deterioration (or gain) of effects, note that most studies had only one follow-up and that assessment usually occurred between 3 and 6 months, not at a more distal 12 months.

Methodological design. Our primary interest is the efficacy of MRE, which is addressed by effect sizes representing the difference between intervention and no intervention. Thus, we included only studies that used control groups. This means we did not include a number of "horse race" studies comparing one intervention with another. Some studies were conducted with classic nointervention control groups $(k=38)$, but most used "waitlist" control groups $(k=73)$. We chose to examine both experimental and quasi-experimental studies because quasi-experimental studies may be more representative of MRE under normal field conditions (Shadish et al., 2000). Experimental studies compared groups randomly assigned to an MRE-treatment or a control group; quasiexperimental studies included a no-treatment control group, but random assignment was not assured. (A full list of MRE studies reviewed but not included in this study, including treatment $\mathrm{A}$ versus treatment B studies, one-group/pre-post design studies, uncodable studies, and studies with duplicate data, is available on request.)

Publication status. We searched extensively for both published and unpublished studies so that we could address publication bias directly. Studies that are not published may be systematically different than published studies, including differences in the intervention effect size. Indeed, meta-analyses that ignore unpublished studies likely overstate the true effect size (e.g., Vevea \& Woods, 2005). More than $60 \%$ of the studies in this meta-analysis were unpublished reports, primarily dissertations. Clinical graduate students conducted the large majority of these unpublished dissertation studies. Some developed their own intervention programs, but most employed well-known programs, such as Couples Communication. The studies generally were well designed but usually suffered from lack of statistical power due to small sample sizes. We suspect that the studies were unpublished primarily due to a lack of statistical power to produce significant results combined with authorship by graduate students who may have been headed toward clinical rather than academic positions.

Foreign language studies. While we did not conduct an exhaustive search for studies published in languages other than English, our search uncovered a handful of reports $(k=4)$ published in other languages (i.e., German, Dutch, Afrikaans). When this occurred, we employed translators to help us code in order to include these studies in our meta-analysis. While program participants in these studies came from non-English-speaking countries with different cultures, they were predominantly White, middle 
class, and educated, similar to samples of U.S. studies, and the programs they received were programs common in the U.S. studies. Moreover, language-inclusive meta-analyses generally provide more precise estimates (Moher et al., 1999).

\section{Search Procedure}

We searched for MRE research conducted over the last three decades (since 1975), when the pace of work in this field began to pick up, through 2006, when substantial federal funding first targeted support for MRE. First, we reviewed 502 studies identified by a search conducted by the Urban Institute for their metaanalysis of MRE (Reardon-Anderson et al., 2005). Second, we searched bibliographies from other meta-analyses and literature reviews. Third, we searched PsycINFO for more recent work (since the Urban Institute search in 2003). Fourth, we searched Dissertation Abstracts International for unpublished work. Finally, we made extensive efforts over the course of 2 years at national conferences and through e-mail to contact researchers and practitioners to find unpublished (and in-press) reports. These search procedures produced 86 codable reports containing 117 independent studies.

\section{Variable Coding}

We created a 55-item codebook to systematically code various moderators relevant to the effect of MRE. Due to space limitations, this study will employ only a handful of those moderators, such as publication status, sample characteristics (i.e., race/ethnicity, relationship distress, gender), and program intensity. (A copy of the codebook is available on request.)

Our coding team for this large collection of studies consisted of four individuals: two $\mathrm{PhD}$ researchers, a trained MS student, and a trained undergraduate student. One coder (MS student) was the "anchor," coding every study. One of the other three individuals was the second coder. After separately coding, the two coders compared answers. When there were discrepancies, coders discussed their rationale and sought further clarification from the study text until they reached agreement. In cases where the two coders were unable to come to a consensus, the coders discussed the differences with the first author until a consensus was reached. Thus, we did not compute inter-coder reliability; rather, we used coder discrepancies as a stimulus for deeper investigation into the study to ascertain the correct coding.

\section{MRE Participants Summary}

Samples in the 117 studies consisted mostly of White, middleclass, married couples in general enrichment programs who were not experiencing significant relationship distress. Only 7 studies had more than $25 \%$ racial/ethnic diversity in their samples; only 4 of these 7 studies had samples that were predominantly non-White. Similarly, only 2 studies had primarily low-income samples; another handful of studies had samples with at least some lowincome couples. (Almost of all these studies came from unpublished dissertations.) There were no reports of homosexual couples in any of these studies. In terms of relationship status, the study samples consisted overwhelmingly of married couples; the number of unmarried, cohabiting couples, when reported, was negligible in enrichment studies. (In programs targeting engaged couples there likely were more cohabiting couples, but this information was seldom provided.) In terms of life-course timing, 3 studies targeted single high-school students, 16 targeted engaged or seriously dating couples, and 10 targeted couples at the transition to parenthood. The remaining $75 \%$ of studies were general marriage enrichment programs (although these samples sometimes included a few engaged or cohabiting couples). There was more variation for relationship length (when reported); the average relationship length was 0-2 years for 18 studies, 3-5 years for 18 studies, 6-10 years for 32 studies, 11-15 years for 30 studies, and 16-20 years for 11 studies. Only about half $(k=61)$ of the studies reported the relationship distress level of the samples. From these reports, there appear to be negligible numbers of distressed couples in the samples of most studies. Eight studies reported that 50\%-89\% of couples in the samples were distressed; 2 studies reported that $90 \%-100 \%$ of couples in the samples were distressed.

\section{Computation and Reporting of Effect Sizes}

The effect size statistic employed is the standardized mean group difference. We adjusted each effect size by using Hedges's (1981) correction for small sample bias. All effect sizes were weighted by the inverse variance (squared standard error) and averaged to create the overall effect size. We employed random effects estimates, as opposed to fixed effects. The random effects model allows for the possibility that differences in effect sizes from study to study are associated not only with participant-level sampling error but also with variations such as study and intervention methods (Lipsey \& Wilson, 2001). In addition, the random effects model allows researchers to generalize beyond the studies included in the meta-analysis (Hedges \& Vevea, 1998). We aggregated effect sizes to the study level because many studies included multiple outcomes. We used Biostat's Comprehensive Meta Analysis II to perform these calculations.

For technical and conceptual reasons, it was wise to conduct analyses separately for experimental and quasi-experimental studies (Lipsey \& Wilson, 2001). Often meta-analysts will include only experimental studies in their analyses because they provide the best evidence of efficacy. However, this also has the potential side effect of excluding significant numbers of studies that also may yield valuable information. In essence, we provide a "benchmark" by analyzing experimental studies first. Then, as suggested by Shadish and Ragsdale (1996), we compare these results with those from quasi-experimental studies. Moreover, rather than combining immediate postassessments and later follow-up assessments, we computed effect sizes separately by time to examine potential deterioration (or gain) in effects.

By analyzing the data in these ways, we encountered the challenge of dealing with a set of effect sizes rather than a single estimate. That is, we generated a set of four effect sizes for each outcome: 2 (design: experimental/quasi-experimental) $\times 2$ (time points: postassessment/follow-up). In addition, we wanted to make a more direct test of deterioration (or gain) of effects. The most direct test of effect size stability from postassessment to follow-up requires limiting our analyses only to those studies that included both an immediate postassessment and a follow-up assessment. Some studies contributed effect sizes only at postassessment with no follow-up, some had no immediate postassessment but did have 
a follow-up, and some studies had both. The first set of analyses described above compares postassessment and follow-up effects across studies, confounding real differences between postassessment and follow-up effects with potential between-study differences. Within-study comparisons that examine only those studies that have both a postassessment and a follow-up do not have this problem. Our overall challenge, then, was to interpret the pattern of effect sizes, as well as individual effects.

\section{Results}

\section{Relationship Quality}

Experimental studies. As seen in Table 1, at the immediate postassessment, the effects of MRE on relationship quality for experimental studies was $d_{e x}=.361(p<.001)$; and at follow-up, $d_{e x}=.306(p<.05)$. When limited to studies with both a postassessment and follow-up, a similar picture emerges of the magnitude and maintenance of MRE on relationship quality, although the effects generally do not reach conventional levels of significance due primarily to small numbers of studies. The postassessment effect size for experimental studies was $d_{e x}=.244$ $(p<.10)$. The follow-up assessment effect size was $d_{e x}=.277$ $(p<.10)$.

Quasi-experimental studies comparison. Using the effect sizes for experimental studies as benchmarks, we compared them with effect sizes for quasi-experimental studies. These effect sizes were generally smaller than those for experimental studies: $d_{q e}=.150$ $(n s)$ at postassessment; $d_{q e}=.195(p<.05)$ at follow-up. When limited to studies that included both a postassessment and a follow-up, the effect sizes were $d_{q e}=.286(p<.10)$ at postassessment; $d_{q e}=.218(p<.10)$ at follow-up. Although experimental effect sizes generally were somewhat larger than quasiexperimental effect sizes, the differences between the two research designs were not significant, although there was a trend for the difference at postassessment $(Q=2.98, p<.10)$.
In sum, the MRE program effects on relationship quality were modest but generally significant-ranging from .24 to .36 -in experimental studies. In quasi-experimental studies, the effects were smaller, but not statistically so-ranging from .15 to .29 . Moreover, immediate postassessment program effects did not diminish significantly at follow-up assessments.

\section{Communication Skills}

Experimental studies. Table 1 also displays our analyses for communication skills. At postassessment, the effects of MRE on communication skills for experimental studies was $d_{e x}=.435$ $(p<.001)$; and at follow-up, $d_{e x}=.448(p<.01)$. When limited to studies that included both a postassessment and a follow-up, a relatively similar picture emerges. The postassessment effect size was $d_{e x}=.539(p<.01)$. The follow-up effect size, however, suggested some deterioration: $d_{e x}=.366(p<.10)$.

Quasi-experimental studies comparison. Using the effect sizes for experimental studies as benchmarks, we compared them with effect sizes for quasi-experimental studies. Again, the effect sizes for communication skills were generally smaller than those for experimental studies: $d_{q e}=.229(p<.01)$ at postassessment; $d_{q e}=.143(n s)$ at follow-up. When limited to studies that included both a postassessment and a follow-up, the effect size was $d_{q e}=$ $.290(p<.05)$ at postassessment; and $d_{q e}=.170(n s)$ at follow-up. Experimental effect sizes were significantly (or near significantly) larger than those for quasi-experimental studies (postassessment $Q=3.86, p<.05$; follow-up $Q=2.84, p<.10$ ) when examining all studies. When examining only studies with both postassessments and follow-up, however, the differences between research design groups were not significant.

Overall, we conclude that MRE program effects on communication skills were modest but significant-ranging from .36 to .54 -for experimental studies. In quasi-experimental studies, the effects were smaller-ranging from .14 to .29 . Moreover, communication skills effects generally did not deteriorate significantly

Table 1

Effect Sizes of MRE on Relationship Quality and Communication Skills, by Study Design

\begin{tabular}{|c|c|c|c|c|c|c|c|}
\hline \multirow[b]{2}{*}{ Outcome/time } & \multicolumn{3}{|c|}{ Experimental studies } & \multicolumn{3}{|c|}{ Quasi-experimental studies } & \multirow{2}{*}{$\begin{array}{c}\begin{array}{c}\text { Design/ } \\
\text { group } \\
\text { difference }\end{array} \\
Q(d f=1)\end{array}$} \\
\hline & $k$ & $d$ & $95 \% \mathrm{CI}$ & $k$ & $D$ & $95 \%$ CI & \\
\hline \multicolumn{8}{|c|}{ Relationship quality } \\
\hline Postassessment & 46 & $.361^{* * * * *}$ & $.189, .533$ & 48 & $.150(n s)$ & $-.018, .317$ & $2.98^{*}$ \\
\hline Follow-up & 22 & $.306^{* *}$ & $.069, .544$ & 34 & $.195^{* * *}$ & $.003, .338$ & $0.51(n s)$ \\
\hline \multicolumn{8}{|c|}{ Post + follow-up studies } \\
\hline Postassessment & 17 & $.244^{*}$ & $-.064, .551$ & 29 & $.286^{* *}$ & $.051, .522$ & $0.00(n s)$ \\
\hline Follow-up & 17 & $.277^{*}$ & $-.014, .568$ & 29 & $.218^{*}$ & $-.003, .439$ & $0.19(n s)$ \\
\hline \multicolumn{8}{|c|}{ Communication skills } \\
\hline Postassessment & 37 & $.435^{* * * * * *}$ & $.280, .589$ & 48 & $.229^{* * * *}$ & $.095, .364$ & $3.86^{* *}$ \\
\hline Follow-up & 18 & $.448^{* * * *}$ & $.170, .727$ & 29 & $.143(n s)$ & $-.077, .364$ & $2.84^{* *}$ \\
\hline \multicolumn{8}{|c|}{ Post + follow-up studies } \\
\hline Postassessment & 13 & $.539^{* * * *}$ & $.199, .879$ & 26 & $.290^{* *}$ & $.053, .528$ & $1.38(n s)$ \\
\hline Follow-up & 13 & $.366^{*}$ & $-.020, .753$ & 26 & $.170(n s)$ & $-.094, .435$ & $0.67(n s)$ \\
\hline
\end{tabular}

Note. Post + follow-up studies refers to those studies that included both an immediate postassessment and a follow-up assessment. MRE $=$ marriage and relationship education; $\mathrm{CI}=$ confidence interval.

${ }^{*} p<.10{ }^{* *} p<.05$. $^{* * * *} p<.01$. $^{* * * * *} p<.001$. 
over time, although a clearer test with only studies that included both a postassessment and follow-up suggested some modest deterioration for experimental studies. Again, quasi-experimental studies generally produced smaller effects, but at follow-up the differences were not significant. Next, we explored possible reasons for the smaller effect sizes in quasi-experimental studies.

\section{Exploring Smaller Effects in Quasi-Experimental Studies}

We found that quasi-experimental studies generally produced smaller effect sizes for both relationship quality and communication skills. Perhaps this is explained partially by the possibility that individuals with greater relationship needs self-selected into psychoeducational treatment (see Shadish et al., 2000) in these studies. Thus, even if their trajectories of change are positive relative to those of control-group participants, differences between treatment and control groups at postassessment may be small. We tested for significant group differences at pretest for quasiexperimental studies, as suggested by Shadish et al. (2000). In randomized studies, group differences at pretest should be zero, but in nonrandomized studies, this assumption may not hold. This was true in our case; we found that the treatment group was significantly lower than the control group at pretest for both relationship quality $\left(d_{q e}=-.153, p<.05\right)$ and communication skills $\left(d_{q e}=-.178, p<.01\right)$. In addition, we examined effect sizes for quasi-experimental studies based on pre-to-post change scores that took account of potential pretest differences. Computing effect sizes based on change scores presented computational challenges because information on the correlation between baseline and postassessments was seldom provided. Noting this imprecision, effect sizes for quasi-experimental studies based on change scores produced effect sizes quite similar to those for experimental studies (and the effect sizes for experimental studies predictably did not change much; analyses are available on request.) Accordingly, pretest differences between treatment and control groups appear to have reduced the postassessment effect sizes difference for quasiexperimental studies.

\section{Moderators of Effect Size Outcomes}

We explored seven variables that could moderate the effect size distributions described so far. (Due to space constraints, we do not include a complete table of these analyses, but a full table is available on request.)

Racial/ethnic, economic diversity, and relationship distress. We explored differences for sample racial/ethnic and economic diversity but found no significant differences for either outcome. However, as we described earlier, the serious lack of sample diversity in MRE evaluation work prevented fair tests of differences. Similarly, we found no evidence of differences by level of sample relationship distress, but the lack of distressed couples in the studies also prevented a fair test.

We did examine qualitatively the few studies that evaluated programs with more racially diverse samples $(k=4)$ and more economically disadvantaged samples $(k=2)$. For instance, Vijayalakshmi (1997) found significant effects of MRE on Indian American couples, and $\mathrm{Wu}$ (1999) found MRE to be effective in improving the relationships of Chinese American couples. Moitinho (2000) also found that MRE was able to improve significantly
Hispanic couples' scores on two dimensions of marital quality. Burnham (1984) found that MRE improved the relationships of low-income couples. In addition, a recently conducted but still unpublished randomized trial has suggested that MRE may help strengthen relationships for lower-income couples (Cowan, Cowan, Pruett, \& Pruett, 2007). Cowan et al. (2007) randomized nearly 300 new-parent couples to receive either a 16-week couple intervention, a 16-week father involvement intervention, or a nointervention control. The couple-intervention group did not decline significantly in relationship satisfaction, but the control and fathering-intervention groups did. Both treatment groups were significantly higher in their levels of father involvement and lower in their levels of conflict about children than was the control group. There were better child outcomes observed for both treatment groups, as well. These effects generally did not differ by ethnicity, income, relationship status, or distress.

Publication status. The large number of unpublished studies in our meta-analysis allowed us to test directly for publication bias. In our primary analyses with experimental studies, in one of four comparisons, published studies produced a significantly larger effect size (for communication skills at follow-up, $Q=5.08, p<$ .05 ; published studies, $k=10, d_{e x}=.695, p<.001$; unpublished studies, $\left.k=8, d_{e x}=.026, n s\right)$. Comparison analyses with quasiexperimental studies yielded no significant differences between published and unpublished studies. Although publication bias does not appear to be a concern for relationship quality, the significantly larger effect for communication skills at postassessment suggests that the inclusion of unpublished studies is needed for an unbiased estimate of effects for this outcome.

Timing of study. For experimental studies assessing relationship quality, we found no evidence that there were significant differences in postassessment effect sizes over time for studies conducted in the approximately three-decade time period of our study $(1975-1985 ; 1986-1995 ; 1996-2006 ; Q=0.42, n s)$. For experimental studies assessing communication skills, the earliest studies seemed to produce stronger effects compared with those of the later studies (1975-1985 studies, $k=13, d_{e x}=.581, p<.001$; 1996-2006 studies, $\left.k=10, d_{\text {ex }}=.296, p<.05\right)$, but this difference did not reach statistical significance $(Q=1.74, n s)$.

Gender. In our primary analyses with experimental studies, there were no significant differences between women's and men's effect sizes, for relationship quality at postassessment (for women, $k=14, d_{\text {ex }}=.170, p<.10$; for men, $k=14, d_{\text {ex }}=.198, p<.05$; $Q=0.04, n s$ ), for relationship quality follow-up (for women, $k=$ $12, d_{e x}=.173, n s$; for men, $\left.k=12, d_{e x}=.219, n s ; Q=0.04, n s\right)$, for communication skills at postassessment (for women, $k=15$, $d_{e x}=.259, p<.01$; for men, $k=15, d_{e x}=.234, p<.05 ; Q=$ $0.04, n s$ ), or for communication skills at follow-up (for women, $k=9, d_{e x}=.447, p<.01$; for men, $k=9, d_{e x}=.440, p<.05$; $Q=0.00, n s)$. Similarly, comparison analyses with quasiexperimental studies yielded no differences. Hence, we find no evidence that MRE produces differential effects for women and men.

Program intensity. There was substantial variation in the length (in hours) of MRE programs, although most fell into a moderate-dosage category. We compared studies of low-dosage programs $(1-8 \mathrm{hr})$ with studies of moderate-dosage programs (9-20 hr); the number of high-dosage programs $(21+\mathrm{hr})$ was too small $(k=9)$ to yield reliable comparisons. Here the pattern was 
clear. In all comparisons for experimental studies, including both relationship quality and communication skills, studies of moderate-dosage programs had substantially larger effect sizes than did low-dosage programs, and most of these differences were statistically significant (or indicated a statistical trend): for experimental studies, relationship quality at postassessment (lowdosage, $k=16, d_{e x}=.179, n s$; moderate-dosage, $k=27, d_{e x}=$ $.468, p<.001 ; Q=3.24, p<.10$ ) and at follow-up (low-dosage, $k=8, d_{\text {ex }}=.115, n s ;$ moderate-dosage, $k=11, d_{\text {ex }}=.520, p<$ $.01 ; Q=1.86, n s)$; and for communication skills at postassessment (low-dosage, $k=15, d_{e x}=.212, p<.01$; moderate-dosage, $k=$ 21, $\left.d_{e x}=.557, p<.001 ; Q=4.68, p<.05\right)$ and at follow-up (low-dosage, $k=6, d_{e x}=-.184$, ns; moderate-dosage, $k=11$, $\left.d_{e x}=.699, p<.001 ; Q=7.62, p<.01\right)$. This same pattern held true for quasi-experimental studies. A survey of the effects associated with the small number of high-dosage programs, however, did not suggest that the most intensive programs yield even larger effect size estimates. Indeed, for quasi-experimental studies, effect sizes for high-dosage programs were generally negative. We speculate that these high-dosage studies attracted more distressed couples, and the more distressed couples were able to self-select into the treatment groups, thus creating the negative differences at postassessment. The highest dosage MRE program, PAIRS, attracts many distressed couples (DeMaria, 2005).

\section{Discussion}

In this meta-analytic study, we coded 86 reports yielding 117 studies that produced more than 500 effect sizes in order to investigate the efficacy of MRE, which is now being used as a public policy tool intended to help couples form and sustain healthy relationships. Before discussing some limitations in this body of work, we review our findings and discuss their possible implications.

\section{Overall}

Our primary analyses, which focused on experimental studies that clearly address efficacy, demonstrated that MRE produces significant, moderate effect sizes on two different outcomes that were commonly examined in MRE studies. For relationship quality, those effects ranged from .24 to .36 . For communication skills, the effects were somewhat larger, ranging from .36 to .54 . Moreover, when follow-up assessments were employed and evaluated, there was not much evidence of diminishing effects, a finding consistent with psychotherapy research on follow-up assessments (Nicholson \& Berman, 1983). However, the most common followups were at 3 or 6 months. Only a handful of studies included follow-up assessments at 12 months or longer. We surveyed these studies to explore whether longer-term follow-ups showed significant effects. Three studies found similar, significant effects with 2-5 year follow-up assessments (i.e., Hahlweg, Markman, Thurmaier, Engl, \& Eckert, 1998; Markman, Floyd, Stanley, \& Storaasli, 1988, for relationship quality; Schulz, Cowan, \& Cowan, 2006), but two other studies did not (e.g., Markman et al., 1988, for communication skills; Van Widenfelt, Hosman, Schaap, \& van der Staak, 1996). Inasmuch as the ultimate goal of MRE is to enhance long-term relationship quality and stability, we should be cautious about asserting long-term effects until a sufficient body of studies is available to address this question. Two current, large-scale demonstration and evaluation studies (see Dion \& Hawkins, 2008) will follow participants over 4-5 years and yield insight into the important question of duration of effects.

While not as strong as therapeutic interventions for couples (Baucom, Hahlweg, \& Kuschel, 2003; Shadish \& Baldwin, 2003), MRE is in the range of effects for other valuable prevention programs. Lipsey and Wilson (1993, see Table 1) reported the effect sizes of a number of prevention programs: parent effectiveness training, $d=.33(k=26)$; maternal sensitivity to newborns programs, $d=.44(k=20)$; adolescent pregnancy prevention programs, $d=.35(k=14)$; alcohol and drug abuse prevention programs, $d=.30(k=98)$; and stress management programs, $d=$ $.75(k=18)$. Thus, it seems reasonable that federal and state policy makers are interested in exploring whether greater availability of MRE services can help more couples form and sustain healthy marriages. Long-term funding of MRE services, however, should be informed by the results of research being conducted now on more disadvantaged couples.

\section{Disadvantaged Couples}

Unfortunately, the research on the effects of MRE with couples from diverse racial/ethnic and economic backgrounds is sparse, making it impossible to draw definitive conclusions about MRE's efficacy for diverse groups. This is a crucial issue because publicly funded programs are being directed primarily at more disadvantaged groups that face greater risks for relationship problems (Ooms \& Wilson, 2004). While we reviewed some emerging evidence that MRE can work for disadvantaged couples (Cowan et al., 2007), more work is clearly needed. Fortunately, both smalland large-scale longitudinal studies with curriculum adapted for disadvantaged populations are now being conducted (Dion \& Hawkins, 2008; see Dion, 2005, for a description of these program adaptations). Similarly, these future studies are likely to contain substantial numbers of couples experiencing more relationship distress than is typical in MRE studies to date. A few studies suggested that distressed couples can benefit from MRE (Kaiser, Hahlweg, Fem-Wolfsdorf, \& Groth, 1998). Halford, Sanders, and Behrens (2001) found that couples at higher risk for divorce benefited more from MRE than did lower risk couples, but future work will provide a better test of this possibility. In 2-5 years we will be in a better position to address the question of the efficacy of MRE programs for more diverse, disadvantaged, and distressed participants. In addition, programs targeting the distinctive needs of remarried couples are rare but increasing (Adler-Baeder \& Higginbotham, 2004). More research about these more complex marriages is needed, as nearly half of marriages in the United States now involve at least one partner who was previously married (Bramlett \& Mosher, 2001).

\section{Communication Skills Versus Relationship Quality}

Overall, this meta-analysis generated somewhat larger effect sizes for communication skills than for relationship quality. We identify three possible explanations for this finding. First, more than two-thirds of the programs in these studies had a primary focus on communication skills training (another 20\% had a secondary focus on it), and researchers typically directly measured 
participants' demonstration of these specific communication skills. Thus, it is not surprising that communication skills would be most affected by the interventions. Second, most of the relationship quality measures were self-reports whereas many of the communication skills assessments were observational. Observational measures of communication skills typically yield higher effect sizes (Blanchard, Hawkins, \& Fawcett, 2007). While couples may be able to display for researchers various communication behaviors learned in MRE, couples may not yet recognize or otherwise attend to positive changes in their overall relationship. In fact, there is some evidence that increases in communication skills can have a negative effect on relationship quality, at least in the short run, presumably because more relationship problems are being attended to but perhaps not fully resolved (Dindia \& Timmerman, 2003). Third, observational methods are subject to reactivity (Heyman, 2001); couples may demonstrate recently learned skills for researchers under observation but not use them in natural settings. Thus, observational methods may overestimate the effects of MRE. If this is the case, then the smaller effect sizes for relationship quality may be better indicators of the true MRE effect size than those for communication skills.

\section{Research Design}

We conducted separate analyses for studies with experimental and quasi-experimental designs, benchmarking quasi-experimental studies against experimental studies. This allowed us to analyze the most comprehensive set of studies to date. Other meta-analytic studies have found substantial effect size differences between different designs, although the direction of bias is not consistent (Lipsey \& Wilson, 1993; Shadish \& Ragsdale, 1996). We found that quasi-experimental studies generated smaller effect sizes than did experimental studies (though not necessarily significantly different). Post hoc analyses, however, suggested that quasiexperimental effect sizes were likely underestimated because pretest treatment-group scores were significantly lower on the outcome measures compared with control-group scores.

We draw two implications from these findings. First, the significant, modest effect sizes generated from the experimental studies provide some assurance that MRE effects are more than selection effects. That is, when randomization procedures are employed, group differences still emerge. Second, the artificial demands of true randomization may not be essential to every MRE program evaluation. Quasi-experimental studies, when they take account of potential pretest group differences, appear to yield similar effects. This should be welcome news to field practitioners who seldom have the resources or the circumstances to conduct evaluations with randomized control groups. Practitioners and evaluators also should be aware that when randomization procedures are not used, then somewhat more distressed couples may self-select into the treatment group.

\section{Other Moderators}

Meta-analysts worry whether published studies, which are easier to find than unpublished studies, overestimate true effects. The problem of publication bias is especially salient in areas of study where sample sizes are generally small (Begg, 1994), which is the case for MRE studies. While numerous techniques have been developed to estimate publication bias indirectly (Begg, 1994), we were able to examine this possibility directly because of our extensive search for unpublished studies that yielded a large number of these studies for our data set. Our analyses uncovered no evidence that published studies upwardly bias effect sizes of MRE on relationship quality. However, there was some evidence that reliance only on published studies may modestly overestimate effects for communication skills, at least at follow-up.

We were able to test for gender differences, but we found no evidence of effect size differences between women and men. This is good news to MRE practitioners who worry that men are less enthused than women about their programs and may benefit less from interventions. Perhaps MRE practitioners could use this information to help with recruiting more men.

In addition, we examined program intensity or dosage as a moderator of effects. We found that moderate-dosage programsbetween $9 \mathrm{hr}$ and $20 \mathrm{hr}$ of instructional time-produced significantly stronger effects than did programs with less instructional time. Moderate dosages of MRE may be necessary to generate desired effects. That is, there may be a threshold of temporal commitment needed to create more substantial change, as some research suggests (Rishel, 2007). However, program intensity may be confounded with program content; more didactic programs generally are shorter than skills-training programs. On the other hand, high-dosage programs $(21+\mathrm{hr})$ did not appear to produce even stronger effects, although there were too few of these studies to produce reliable conclusions. Our findings seem to correspond to findings from a large, cross-sectional survey of participation in premarital education (Stanley, Amato, Johnson, \& Markman, 2006). These researchers found no further positive effect on marital satisfaction after about $20 \mathrm{hr}$ of premarital instruction. They also found an effect of premarital education on decreasing conflict but this effect diminished after about $10 \mathrm{hr}$ of instruction. The modal dosage we found in our meta-analysis was about $12 \mathrm{hr}$. While more analysis of dosage is needed, taken with the Stanley et al. (2006) findings, our findings suggest that moderate dosages may be about the right intensity, at least for middle-class, nondistressed couples.

\section{Further Critique: Limited Outcomes}

MRE researchers have studied a limited range of outcomes, namely variables that primarily address relationship quality and communication skills. Moore and her colleagues (Moore et al., 2004) have suggested a multi-dimensional definition for healthy relationships that is being used to guide the federal Healthy Marriage Initiative. Many of those dimensions of a healthy relationship are understudied as outcomes in MRE research. For instance, only a handful of studies have examined indicators of marital stability or divorce propensity. This is a crucial outcome, because the stability of the relationship has important consequences beyond its quality (Amato, Booth, Johnson, \& Rogers, 2007). Similarly, few MRE studies include measures of relationship aggression. This is a crucial outcome relevant to the quality of the couple relationship and the well-being of children in that relationship. It is also an important concern for policy makers supporting MRE with public funds (Roberts, 2006). Finally, intervention effects on important relationship virtues, such as commitment, sacrifice, and forgiveness (Fincham et al., 2007; Fowers, 2000) are seldom reported in 
the research. Yet many MRE curricula address these virtues because they are important elements of healthy relationships. If relationship virtues can be strengthened, then MRE researchers should give these outcomes more attention. The hegemonic focus on relationship quality and communication skills is curious given that these are only two of the many known predictors of divorce (Amato et al., 2007; Karney \& Bradbury, 1995). Finally, MRE studies have not directly linked adult relationship changes to child outcomes. From a policy perspective, MRE effects on adults will be most valuable when they are linked to children's well-being. Accordingly, we recommend that future MRE researchers regularly assess measures of relationship stability, aggression, and virtues, and consider including child outcome measures, as well.

\section{Further Critique: Design Challenges}

MRE researchers have not attended to the potential fuzziness inherent in simple "treatment" and "no-treatment" designs. For instance, many MRE studies employ waitlist control groups that enroll couples who volunteer for intervention but are told they need to wait, sometimes for as long as a year, before beginning treatment. Given that many couples volunteer because they want help, negative effects could emerge during the wait period. In addition, treatment couples anticipating intervention likely have expectations that may initiate positive change even before treatment begins, what psychotherapy researchers term "pretreatment change" (Weiner-Davis, de Shazer, \& Gingerich, 1987). For some couples, the initial choice simply to focus on their relationship, regardless of the treatment specifics, may create meaningful, positive change. Treatment versus no-treatment comparisons do not address these confounds. Psychotherapy researchers have attempted to address these issues (e.g., Wampold, Minami, Tierney, Baskin, \& Bhati, 2005), but these confounds have not been given serious attention by MRE evaluation researchers. Little MRE research has explicitly studied the mechanisms of change, or the "active ingredients," in MRE, as well as the moderators and mediators of change. Perhaps this meta-analysis provides enough support for the general effectiveness of MRE so that future research can now concentrate on understanding how change occurs. This kind of understanding would lead to the design of even stronger interventions.

\section{Further Meta-Analytic Research}

Finally, we reflect on further meta-analytic work that would be valuable. We have examined undifferentiated outcomes in this study: relationship quality and communication skills. In fact, however, these undifferentiated constructs also deserve a more finegrained examination. For instance, although we examined the effect sizes of MRE programs on any aspect of communication, treating communication as a global construct may have obscured important distinctions (S. Wilson \& Sabee, 2003), including observed versus self-report measures, and positive and negative communication constructs. Similarly, relationship satisfaction and relationship quality can be seen as distinct constructs (Amato et al., 2007). Some scholars argue that marital quality is not unidimensional; rather, positive and negative evaluations of the relationship are distinct (though related) dimensions and should be measured as such (Bradbury, Fincham, \& Beach, 2000). Future meta-analytic studies should test whether different approaches for measuring relationship quality yield different effect size estimates. In addition, because our focus was on the efficacy of MRE, we excluded from our analyses a large number of evaluation studies employing one-group/pre-post designs, or comparing one treatment with another treatment (38 reports yielding 67 codable studies; see for instance, Halford et al., 2001). Yet many of these studies were well conceptualized and reported results that could shed further light on the practice of MRE if they can yield data appropriate for metaanalysis. Future meta-analysis should consider how to make better use of these studies.

\section{Conclusion}

MRE recently has gone beyond private psychoeducational programs to become a tool of social policy to help couples form and sustain healthy relationships. The results of our meta-analysis demonstrate the efficacy of MRE for White, middle-class couples; MRE produces modest but reliable effects comparable with those of other psychoeducational interventions of interest to policy makers. However, the question of efficacy for more diverse and disadvantaged samples remains an important area for research that will inform practitioners and policy makers. Moreover, having demonstrated the efficacy of MRE, at least with White, middleclass samples, the challenge now for practitioners and evaluation researchers is to develop even better interventions that produce stronger effects for relationship stability and quality.

\section{References}

References marked with an asterisk (*) indicate studies included in the meta-analysis.

*Adam, D., \& Gingras, M. (1982). Short- and long-term effects of a marital enrichment program upon couple functioning. Journal of Sex \& Marital Therapy, 8(2), 97-118.

Adler-Baeder, F., \& Higginbotham, B. (2004). Implications of remarriage and stepfamily formation for marriage education. Family Relations, 53, $448-458$.

*Adler-Baeder, F., Kerpelma, J. J., Schramm, D., Higginbotham, B. J., \& Paulk, G. A. (2007). The impact of relationship education on adolescents of diverse backgrounds. Family Relations, 56, 291-303.

Administration for Children and Families. (2007). Healthy marriage initiative: Activities and accomplishments 2006. Washington, DC: Author.

Amato, P. R., Booth, A., Johnson, D. R., \& Rogers, S. J. (2007). Alone together: How marriage in America is changing. Cambridge, MA: Harvard University.

*Anderson, L. D. (1984). The effects of a home-based, audio cassette marriage enrichment course on marital communication and marital adjustment. Dissertation Abstracts International, 45, 1989A. (UMI No. 8423850)

*Bagarozzi, D. A., Bagarozzi, J. I., Anderson, S. A., \& Pollane, L. (1984). Premarital Education and Training Sequence (PETS): A 3-year follow-up of an experimental study. Journal of Counseling and Development, 63, 91-100.

Baucom, D. H., Hahlweg, K., \& Kuschel, A. (2003). Are waiting-list control groups needed in future marital therapy research? Behavior Therapy, 34, 179-188.

Begg, C. B. (1994). Publication bias. In H. Cooper \& L. V. Hedges (Eds.), The handbook of research synthesis (pp. 399-410). New York: Russell Sage Foundation.

*Biderman, R. (1982). The effects of the Minnesota Couples Communication Program on communication, adaptability and cohesion: A quasi- 
experimental investigation. Dissertation Abstracts International, 43, 2600A. (UMI No. 8301907)

Blanchard, V. L., Hawkins, A. J., \& Fawcett, E. B. (2007, November). Does relationship education improve couples' communication? A metaanalysis. Poster presented at the National Council on Family Relations Annual Conference, Pittsburg, PA.

*Bodenmann, G., Charvoz, L., Cina, A., \& Widmer, K. (2001). Prevention of marital distress by enhancing the coping skills of couples: 1-year follow-up study. Swiss Journal of Psychology, 60(1), 3-10.

*Boike, D. E. (1977). The impact of a premarital program on communication process, communication facilitativeness, and personality trait variables of engaged couples. Dissertation Abstracts International, 38 (5-A), 3083. (UMI No. 77-24,740)

Bradbury, T. N., Fincham, F. D., \& Beach, S. R. H. (2000). Research on the nature and determinants of marital satisfaction: A decade in review. Journal of Marriage and the Family, 62, 964-980.

Bramlett, M. D., \& Mosher, W. D. (2001). First marriage dissolution, divorce, and remarriage: United States. Advance data from vital and health statistics (No. 323). Hyattsville, MD: National Center for Health Statistics.

*Braukhaus, C., Hahlweg, K., Kröger, C., Groth, T., \& Fehm-Wolfsdorf, G. (2001). Darf es ein wenig mehr sein? Zur wirksamkeit von auffrischungssitzungen bei derpPrävention von beziehungsstörungen [A little bit more? The impact of adding booster sessions to a prevention training program for marital distress]. Verhaltenstherapie, 11, 56-62.

*Brock, G. W. (1978). Unilateral marital intervention: Training spouses to train their partners in communication skills. Dissertation Abstracts International, 39 (11-B), 5511-5512. (UMI No. AAT 7909049)

*Brock, G. W., \& Joanning, H. (1983). A comparison of the Relationship Enhancement Program and the Minnesota Couple Communication Program. Journal of Marital and Family Therapy, 9(4), 413-421.

*Brown, J. O. (1993). Effects of Adventist engaged encounter on role expectations and growth in premarital relations. Dissertation Abstracts International, 54, 2750A. (UMI No. 9334292)

*Bryan, A. A. M. (1995). Effect of community based intervention on relationship quality in expectant parent couples. Dissertation Abstracts International, 56, 3689B. (UMI No. 9537841)

*Burnham, R. A. (1984). Effects of the Couple Communication Program on marital and family communication of high and low socioeconomic status couples. Dissertation Abstracts International, 45, 1006B. (UMI No. 8414128$)$

*Busick, C. A. (1982). The effects of communication training on marital communication, marital satisfaction and self-concept. Dissertation Abstracts International, 43 (3-A), 725. (UMI No. 8219094)

Butler, M. H., \& Wampler, K. S. (1999). A meta analytic update of research on the Couple Communication program. The American Journal of Family Therapy, 27, 223-237.

*Carpenter, K. M. (1995). Prevention of the decline of marital satisfaction during the transition to parenthood: A pilot test of a marital skills training workshop. Masters Abstracts International, 34, 878. (UMI No. 1376203)

Carroll, J. S., \& Doherty, W. H. (2003). Evaluating the effectiveness of premarital prevention programs: A meta-analytic review of outcome research. Family Relations, 53, 105-118.

*Carson, J. W., Carson, K. M., Gil, K. M., \& Baucom, D. H. (2004). Mindfulness-based relationship enhancement. Behavioral Therapy, 35, 471-494.

*Chambers, F. A. (1986). A comparison of the effects of the Couple Communication II Program and a family of origin workshop on marital satisfaction and individual autonomy. Dissertation Abstracts International, 47, 3311A. (UMI No. 8700426)

*Combs, C. W. (1994). The effect of cognitive-behavioral marriage enrichment on marital adjustment among church couples. Dissertation Abstracts International, 55, 1170B. (UMI No. 9419686)
Cooper, A., \& Stoletenberg, C. D. (1987). Comparison of sexual enhancement and a communication-training program on sexual and marital satisfaction. Journal of Counseling Psychology, 34, 309-314.

*Cottle, L. T. (1987). Effects of training conditions upon married couples' empathic ability, perception of spouse's empathy, marital intimacy, and marital satisfaction. Dissertation Abstracts International, 49, 746A. (UMI No. 8805329)

*Coutta, E. R. (2001). An investigation into the significance of an acceptance-based marital enrichment group on couple intimacy and acceptance. Dissertation Abstracts International, 62, 5958. (UMI No. 3035550)

Cowan, P. A., Cowan, C. P., Pruett, M., \& Pruett, K. (2007, June). Supporting father involvement in low-income families: Interventions for fathers and couples. Paper presented at the Administration for Children and Families Welfare Research Conference, Crystal City, VA.

*Cullen, H. F. (1985). The effects of participation in marriage encounter on marital communication and marital satisfaction. Dissertation Abstracts International, 46, 2866 (UMI No. 8521062)

*Davis, G. M. (1979). The differential effect of married couple communication training in groups with the spouse present and spouse not present Dissertation Abstracts International, 40, 4023. (UMI No. 8005031)

"Davis, M. W. (1995). An experimental study of the "Growing Together" marriage preparation program. Dissertation Abstracts International, 56, 2563A. (UMI No. 9540237)

*Delaney, J. E., II. (1993). The effects of participation in a marital preparation program on couple compatibility. Dissertation Abstracts International, 55, 6701B. (UMI No. 9413231)

DeMaria, R. M. (2005). Distressed couples and marriage education. Family Relations, 54, 242-253.

Dindia, K., \& Timmerman, L. (2003). Accomplishing romantic relationships. In B. R. Burleson \& J. O. Greene (Eds.), Handbook of communication and social interaction skills (pp. 685-721). Mahwah, NJ: Erlbaum.

Dion, M. R. (2005). Health marriage programs: Learning what works. The Future of Children, 15(2), 139-156.

Dion, M. R., \& Hawkins, A. J. (2008). Federal policy efforts to improve outcomes among disadvantaged families by supporting marriage and family stability. In D. Russell Crane \& Tim B. Heaton (Eds.), Handbook of families and poverty (pp. 411-425). Thousand Oaks, CA: Sage.

*Dode, I. L. (1979). An evaluation of the Minnesota Couples Communication Program: A structured educational enrichment experience. Dissertation Abstracts International, 40, 1211A. (UMI No. 79-20, 500)

*Duffey, T. H., Wooten, H. R., Lumadue, C. A., \& Comstock, D. C. (2004). The effects of dream sharing on marital intimacy and satisfaction. Journal of Couple \& Relationship Therapy, 3(1), 53-68.

*Duncan, S. F., Steed, A., \& Martino, C. (2007). Comparing Web-based and traditional family life education on outcomes for marriage. Manuscript submitted for publication.

*Durana, C. (1996a). Bonding and emotional reeducation of couples in the PAIRS training: Part II. The American Journal of Family Therapy, 24(4), 315-328.

*Durana, C. (1996b). A longitudinal evaluation of the effectiveness of the PAIRS psychoeducational program for couples. Family Therapy, 23(1), $11-36$.

*Farris, D. W., \& Avery, A. W. (1980). Training marital couples in problem-solving skills: An evaluation of a weekend training format. Family Therapy, 7(2), 83-96.

Fincham, F. D., Stanley, S. M., \& Beach, S. R. H. (2007). Transformative processes in marriage: An analysis of emerging trends. Journal of Marriage and Family, 69, 275-292.

Flay, B. R., Biglan, A., Boruch, R. F., Castro, F. G., Gottfredson, D., Kellam, S., et al. (2005). Standards of evidence: Criteria for efficacy, effectiveness, and dissemination. Prevention Science, 6, 151-175. 
"Floyd, F. J. (1988). Couples' cognitive/affective reactions to communication behaviors. Journal of Marriage and the Family, 50, 523-532.

Fowers, B. J. (2000). Beyond the myth of marital happiness. San Francisco: Jossey-Bass.

*Gardner, S. P., \& Boellaard, R. (2006, November). Does youth relationship education work after high school? A longitudinal study. Poster presented at the National Council on Family Relations, Minneapolis, MN.

*Gardner, S. P., Giese, K., \& Parrot, S. M. (2004). Evaluation of the connections: Relationships and marriage curriculum. Family Relations, 53(5), 521-527.

Giblin, P., Sprenkle, D. H., \& Sheehan, R. (1985). Enrichment outcome research: A meta-analysis of premarital, marital and family interventions. Journal of Marital and Family Therapy, 11(3), 257-271.

Gottman, J. M., \& Silver, N. (1999). The seven principles for making marriage work. New York: Crown.

*Griffin, J. M., Jr., \& Apostal, R. A. (1993). The influence of relationship enhancement training on differentiation of self. Journal of Marital and Family Therapy, 19(3), 267-272.

Hahlweg, K., \& Markman, H. J. (1988). Effectiveness of behavioral marital therapy: Empirical status of behavioral techniques in preventing and alleviating marital distress. Journal of Consulting and Clinical Psychology, 56, 440-447.

*Hahlweg, K., Markman, H. J., Thurmaier, F., Engl, J., \& Eckert, V. (1998). Prevention of marital distress: Results of a German prospective longitudinal study. Journal of Family Psychology, 12(4), 543-556.

Halford, W. K. (2004). The future of couple relationship education: Suggestions on how it can make a difference. Family Relations, 53, 559566.

Halford, W. K., Markman, H. J., Kline, G. H., \& Stanley, S. M. (2003). Best practices in couple relationship education. Journal of Marital and Family Therapy, 29, 385-406.

*Halford, W. K., Moore, E., Wilson, K. L., Farrugia, C., \& Dyer, C. (2004). Benefits of flexible delivery relationship education: An evaluation of the Couple CARE Program. Family Relations, 53, 469-476.

Halford, W. K., Sanders, M. R., \& Behrens, B. C. (2001). Can skills training prevent relationship problems in at-risk couples? Four-year effects of a behavioral relationship education program. Journal of Family Psychology, 15, 750-768.

"Harrington, C. M. (1998). A comparative evaluation of the effectiveness of two marriage preparation programs: A look at the importance of communication skill training. Dissertation Abstracts International, 60, 366. (UMI No. 9916054)

*Hawkins, A. J., Fawcett, E. B., Carroll, J. S., \& Gilliland, T. T. (2006). The Marriage Moments program for couples transitioning to parenthood: Divergent conclusions from formative and outcome evaluation data. Journal of Family Psychology, 20, 561-570.

*Hawley, D. R., \& Olson, D. H. (1995). Enriching newlyweds: An evaluation of three enrichment programs. The American Journal of Family Therapy, 23(2), 129-147.

Hedges, L. V. (1981). Distribution theory for Glasser's estimator of effect size and related estimators. Journal of Educational Statistics, 6, 107128.

Hedges, L. V., \& Vevea, J. L. (1998). Fixed- and random-effects models in meta-analysis. Psychological Methods, 3, 486-504.

Heyman, R. E. (2001). Observation of couple conflicts: Clinical assessment applications, stubborn truths, and shaky foundations. Psychological Assessment, 13, 5-35.

"Hickmon, W. A., Jr. (1994). Analysis of an adventure-based marriage enrichment program. Dissertation Abstracts International, 54, 4038A. (UMI No. 9403853)

Hight, T. L. (2000). Do the rich get richer? A meta-analysis of the methodological and substantive moderators of couple enrichment. Dissertation Abstracts International, 61, 3278 (UMI No. 3118673)
*Hollis, K. A. (2004). Examining the impact of a psycho-spiritual educational model of marriage enrichment on seminary couples: A pilot study. Dissertation Abstracts International, 65, 181. (UMI No. 3118673)

*Hoskins, J. T. (1984). A comparison of skill-enhancement interventions with step-parenting couples. Dissertation Abstracts International, 45, 3549A. (UMI No. 8501999)

*Huber, J. W. (1978). The effects of dialogue communication upon the interpersonal marital relationship. Dissertation Abstracts International, 38, 3883B. (UMI No. 7732481)

Huston, T. L., \& Melz, H. (2004). The case for (promoting) marriage: The devil is in the details. Journal of Marriage and Family, 66, 943-958.

*Kaiser, A., Hahlweg, K., Fehm-Wolfsdorf, G., \& Groth, T. (1998). The efficacy of a compact psychoeducational group training program for married couples. Journal of Consulting and Clinical Psychology, 66(5), 753-760.

Karney, B. R., \& Bradbury, T. N. (1995). The longitudinal course of marital quality and stability: A review of theory, method, and research. Psychological Bulletin, 118, 3-34.

*Lane, M. T. (1993). An evaluation of a self-instructional marital enrichment training program. Dissertation Abstracts International, 55, 1531A. (UMI No. NN87866)

Larson, J. H. (2004). Innovations in marriage education: Introduction and challenges. Family Relations, 53, 421-424.

"Larson, J. H., Vatter, R. S., Galbraith, R. C., Holman, T. B., \& Stahmann, R. F. (2007). The RELATionship Evaluation (RELATE) with therapistassisted interpretation: Short-term effects on premarital relationships. Journal of Marital and Family Therapy, 33, 364-374.

"Larson, K. B. (1976). The effects of communication training in small groups upon self-disclosure, marital adjustment, and emotional attachment in marriage. Dissertation Abstracts International, 37, 5328B. (UMI No. 7708453)

Lipsey, M. W., \& Wilson, D. B. (1993). The efficacy of psychological, educational, and behavioral treatment: Confirmation from meta-analysis American Psychologist, 48, 1181-1209.

Lipsey, M. W., \& Wilson, D. B. (2001). Practical meta-analysis. Thousand Oaks, CA: Sage.

*Litty, C. L. E. (1988). An investigation of the effects of an Adlerian group couple education program on premarital adjustment. Dissertation $A b$ stracts International, 49, 2541A. (UMI No. 8825628)

Locke, H., \& Wallace, K. (1959). Short marital adjustment and prediction tests: Their reliability and validity. Marriage and Family Living, 21, 251-255.

"Lovejoy, K. A. R. (2004). Marriage Moments: An evaluation of an approach to strengthen couples' relationships during the transition to parenthood in the context of a home visitation program. Unpublished master's thesis, Brigham Young University.

*Markman, H. J., Floyd, F. J., Stanley, S. M., \& Storaasli, R. D. (1988). Prevention of marital distress: A longitudinal investigation. Journal of Consulting and Clinical Psychology, 56(2), 210-217.

*Meadors, R. E. (1989). Marriage enrichment: An emerging specialty of prevention in the field of marital counseling. Dissertation Abstracts International, 51, 2270A. (UMI No. 9032212)

*Meadors, W. K. (1994). The effects of a partially structured marriage enrichment weekend program on couples' perception of marital communication and adjustment changes. Dissertation Abstracts International, 55, 1192A. (UMI No. 9428375)

*Midmer, D., Wilson, L., \& Cummings, S. (1995). A randomized, controlled trial of the influence of prenatal parenting education on postpartum anxiety and marital adjustment. Family Medicine, 27(3), 200-205.

*Milholland, T. A., \& Avery, A. W. (1982). Effects of Marriage Encounter on self-disclosure, trust and marital satisfaction. Journal of Marital and Family Therapy, 8(2), 87-89.

"Miller, S., Nunnally, E. W., \& Wackman, D. B. (1976). A communication training program for couples. Social Casework, 57(1), 9-18. 
Moher, D., Cook, D. J., Eastwood, S., Olkin, I., Rennie, D., Stroup, D. F., for the QUOROM Group. (1999, November 27). Improving the quality of reports of meta-analyses of randomized controlled trials: The QUORUM statement. The Lancet, 354, 1896-1900.

*Moitinho, E. S. L. (2000). The effects of marriage enrichment conferences on marital satisfaction of English-speaking Hispanic married couples. Dissertation Abstracts International, 61, 2213-2341. (UMI No. 9968727)

Moore, K. A., Jekielek, S. M., Bronte-Tinkew, J., Guzman, L., Ryan, S., \& Redd, Z. (2004). What is a "healthy marriage"? Defining the concept. In Child trends research brief (Publication \#2004-16). Washington, DC: Child Trends.

Nicholson, R. A., \& Bermen, J. S. (1983). Is follow-up necessary in evaluating psychotherapy? Psychological Bulletin, 93, 261-278.

*Odegard, M. M. (1983). The efficacy of a proactive marital enrichment program for dual-career couples. Dissertation Abstracts International, 44, 1736A. (UMI No. 8324432)

Ooms, T., Bouchet, S., \& Parke, M. (2004). Beyond marriage licenses: Efforts in states to strengthen marriage and two-parent families, a state-by-state snapshot. Washington, DC: Center for Law and Social Policy.

Ooms, T., \& Wilson, P. (2004). The challenges of offering relationship and marriage education to low-income populations. Family Relations, 53, 440-447.

*Perlow, S. P. (1985). An evaluation of a weaning procedure in increasing the maintenance of a couple communication training program. Dissertation Abstracts International, 46, 3604A. (UMI No. 8523967)

*Petch, J. F., Halford, W. K., \& Creedy, D. (2006). Promoting a positive transition to parenthood: A randomized controlled trial of the Couple Care for Parents program. Manuscript submitted for publication.

*Pretorius, H. G., van Wyk, J. D., \& Scheppers, J. M. (1992). Die evaluering van ' $n$ huweliksvoorbereidingsprogram [The evaluation of a marital preparation program]. South African Journal of Psychology, 22(3), 140-146.

*Ramsay, A. J. (1989). Marriage enrichment: The use of computers to teach communication skills. Dissertation Abstracts International, 50, 2390A. (UMI No. 8921250)

Reardon-Anderson, J., Stagner, M., Macomber, J. E., \& Murray, J. (2005). Systematic review of the impact of marriage and relationship programs. Washington, DC: Administration for Children and Families, U.S. Department of Health \& Human Services.

*Reissman, C., Aron, A., \& Bergen, M. R. (1993). Shared activities and marital satisfaction: Causal direction and self-expansion versus boredom. Journal of Social and Personal Relationships, 10, 243-254.

*Ripley, J. S., \& Worthington, E. L., Jr. (2002). Hope-focused and forgiveness-based group interventions to promote marital enrichment. Journal of Counseling and Development, 80, 452-463.

Rishel, C. W. (2007). Evidence-based practice in mental health: What is it and how do we get there. American Journal of Orthopsychiatry, 77, 153-164.

Roberts, P. (2006). Building bridges between the healthy marriage, responsible fatherhood, and domestic violence movements: Issues, concerns, and recommendations. In CLASP Policy Brief (Brief No. 7). Washington, DC: Center for Law and Policy.

*Saiz, C. C. (2001). Teaching couples communication and problem-solving skills: A self-directed, videotaped version of the prevention relationship enhancement program (PREP). Dissertation Abstracts International, 62, 2076B. (UMI No. 3010927)

*Samko, M. R. (1976). Self-disclosure and marital communication as a function of participation in a marriage workshop and the subsequent use of a communication technique. Dissertation Abstracts International, 38, 4478B. (UMI No. 7732498)

*Schaffer, M. (1980). An evaluation of the Minnesota Couple Communi- cation program upon communication of married couples. Dissertation Abstracts International, 41, 4643B. (UMI No. 8109897)

*Schollenberger, M. A. (2001). Increasing marital adjustment in graduate students and their spouses through Relationship Enhancement. Dissertation Abstracts International, 64, 75A. (UMI No. 3077398)

*Schulz, M. S., Cowan, C. P., \& Cowan, P. A. (2006). Promoting healthy beginnings: A randomized controlled trial of a preventive intervention to preserve marital quality during the transition to parenthood. Journal of Consulting and Clinical Psychology, 74, 20-31.

*Schwartz, R. C. (1980). The relationship among communication style, self esteem, and the Couple Communication Program. Dissertation Abstracts International, 41, 3198. (UMI No. 8102705)

Shadish, W. R., \& Baldwin, S. A. (2003). Meta-analysis of MFT interventions. Journal of Marital and Family Therapy, 29, 547-570.

Shadish, W. R., Matt, G. E., Navarro, A. M., \& Phillips, G. (2000). The effects of psychological therapies under clinically representative conditions: A meta-analysis. Psychological Bulletin, 126, 512-529.

Shadish, W. R., \& Ragsdale, K. (1996). Random versus nonrandom assignment in controlled experiments: Do you get the same answers? Journal of Consulting and Clinical Psychology, 64, 1290-1305.

*Shapiro, A. F., \& Gottman, J. M. (2005). Effects on marriage of a psycho-communicative-educational intervention with couples undergoing the transition to parenthood, evaluation at 1-year post intervention. The Journal of Family Communication, 5(1), 1-24.

Spanier, G. B. (1976). Measuring dyadic adjustment: New scales for assessing the quality of marriage and similar dyads. Journal of Marriage and the Family, 38, 15-28.

*Stafford, R. R. (1978). Attitude and behavior change in couples as a function of communication training. Dissertation Abstracts International, 39, 2526B. (UMI No. 7819902)

Stanley, S. M., Amato, P. R., Johnson, C. A., \& Markman, H. J. (2006). Premarital education, marital quality, and marital stability: Findings from a large, random household survey. Journal of Family Psychology, 20(1), 117-126.

*Steller, J. B. (1979). The effects of Couples Communication training upon individualized goals, marriage adjustment, self disclosure, and the use of communication skills by married couples. Dissertation Abstracts International, 40, 900B. (UMI No. 7918397)

*Strickland, J. H. (1981). The effects of two marriage enrichment retreat models on marital satisfaction. Dissertation Abstracts International, 42 (10-A), 4305. (UMI No. 8206581)

*Thompson, K. B. (1978). The effectiveness of Couples Communication training on interpersonal orientation, couple communication, perceptual congruence, and verbal communication style: A field study. Dissertation Abstracts International, 39, 3009B. (UMI No. 7822768)

*Trathen, D. W. (1995). A comparison of the effectiveness of two Christian premarital counseling programs (skills and information based) utilized by evangelical protestant churches. Dissertation Abstracts International, 56, 2277A. (UMI No. 9532956)

*Turner, L. (1998). The impact of a psychoeducational group intervention on marital discord, adult interaction style, projective identification, and perceptive identification. Dissertation Abstracts International, 59, 1337-1647. (UMI No. 9828838)

*Valenti, F. T. (1989). Effects of the Couple Communication Program I on the marital adjustment, self-disclosure, and communication style of therapy and non-therapy participants. Dissertation Abstracts International, 49, 1715A. (UMI No. 8816361)

*van der Molen, H. T., Gramsbergen-Hoogland, Y., Wolters, F. J. M., \& de Meijer, M. (1987). Effecten van een communicatie-cursus voor (echt) paren [Effects of a communication course for married couples]. Tijdschrift Voor Psychotherapie, 13(3), 114-127.

*Van Widenfelt, B., Hosman, C., Schaap, C., \& van der Staak, C. (1996). The prevention of relationship distress for couples at risk: A controlled 
evaluation with nine-month and two-year follow-ups. Family Relations, $45,156-165$.

Vevea, J. L., \& Woods, C. M. (2005). Publication bias in research synthesis: Sensitivity analysis using a priori weight functions. Psychological Methods, 30, 428-443.

*Vijayalakshmi, O. P. (1997). Enriching marital communication and marital adjustment of couples from India living in the United States. Dissertation Abstracts International, 58, 1605A. (UMI No. 9734852)

*Wampler, K. S., \& Sprenkle, D. H. (1980). The Minnesota Couple Communication Program: A follow-up study. Journal of Marriage and the Family, 42(3), 577-584.

Wampold, B. E., Minami, T., Tierney, S. C., Baskin, T. W., \& Bhati, K. S. (2005). The placebo is powerful: Estimating placebo effects in medicine and psychotherapy from randomized clinical trials. Journal of Clinical Psychology, 61(7), 835-854.

*Warner, M. D. (1981). Comparison of a religious marriage enrichment program with an established communication training enrichment program. Dissertation Abstracts International, 42, 3774A. (UMI No. 8200747)

Weiner-Davis, M., de Shazer, S., \& Gingerich, W. J. (1987). Building on pretreatment change to construct the therapeutic solution: An exploratory study. Journal of Marital and Family Therapy, 13, 359-363.

*Wilkinson, L. L. H. (1983). Consensus model training for couples: An outcome study of an integrated conflict management program for marriage enrichment. Dissertation Abstracts International, 44, 993A. (UMI No. 8317704)

"Wilson, D. A. (1980). The effects of a partially structured Christian marriage enrichment program upon marital communication, general marital adjustment, and purpose in life. Dissertation Abstracts International, 41, 1506-1707. (UMI No. 8023455)

Wilson, S., \& Sabee, C. M. (2003). Explicating communicative competence as a theoretical term. In J. O. Greene \& B. R. Burleson (Eds.), Handbook of communication and social interaction skills (pp. 3-50). Mahwah, NJ: Erlbaum.

*Witkin, S. L., Edleson, J. L., Rose, S. D., \& Hall, J. A. (1983). Group training in marital communication: A comparative study. Journal of Marriage and the Family, 45(3), 661-669.

*Worthington, E. L., Jr., Buston, B. G., \& Hammonds, T. M. (1989). A component analysis of marriage enrichment: Information and treatment modality. Journal of Counseling and Development, 67, 555-560.

Worthington, E. L., Jr., Hight, T. L., Ripley, J. S., Perrone, K. M., Kurusu, T. A., \& Jones, D. R. (1997). Strategic hope-focused relationshipenrichment counseling with individuals. Journal of Counseling Psychology, 44, 381-389.

*Wu, D. J. (1999). Developing and implementing a Christian marriage enrichment program for Chinese immigrants. Dissertation Abstracts International, 60, 1785A. (UMI No. 9930611)

*Yarbrough, D. M. (1983). Effects of structured negotiation training on dyadic adjustment, satisfaction, and intimacy. Dissertation Abstracts International, 44, 2422A. (UMI No. 8326439)

Received July 26, 2007

Revision received March 25, 2008 Accepted April 18, 2008

\section{Call for Nominations}

The Publications and Communications (P\&C) Board of the American Psychological Association has opened nominations for the editorships of Developmental Psychology, Journal of Consulting and Clinical Psychology, and Psychological Review for the years 2011-2016. Cynthia García Coll, $\mathrm{PhD}$, Annette M. La Greca, PhD, and Keith Rayner, PhD, respectively, are the incumbent editors.

Candidates should be members of APA and should be available to start receiving manuscripts in early 2010 to prepare for issues published in 2011. Please note that the P\&C Board encourages participation by members of underrepresented groups in the publication process and would particularly welcome such nominees. Self-nominations are also encouraged.

Search chairs have been appointed as follows:

- Developmental Psychology, Peter A. Ornstein, PhD, and Valerie Reyna, $\mathrm{PhD}$

- Journal of Consulting and Clinical Psychology, Norman Abeles, $\mathrm{PhD}$

- Psychological Review, David C. Funder, PhD, and Leah L. Light, PhD

Candidates should be nominated by accessing APA's EditorQuest site on the Web. Using your Web browser, go to http://editorquest.apa.org. On the Home menu on the left, find "Guests." Next, click on the link "Submit a Nomination," enter your nominee's information, and click "Submit."

Prepared statements of one page or less in support of a nominee can also be submitted by e-mail to Emnet Tesfaye, P\&C Board Search Liaison, at etesfaye@apa.org.

Deadline for accepting nominations is January 10, 2009, when reviews will begin. 